\title{
Challenging Your Implicit Leadership Theory
}

\author{
Wiley W. Souba, MD, ScD, MBA \\ Professor of Surgery, Geisel School of Medicine \\ Dartmouth College \\ Matthew H. Souba, MSc, MLitt \\ Doctoral Student, Department of Philosophy \\ Ohio State University
}

\begin{abstract}
Each of us has an implicit leadership theory, a mental model we are largely unaware of, that represents the skills, traits, and qualities that define effective leaders. Curiously, the peerreviewed literature has reported almost exclusively on the ideal attributes of leaders, overlooking the axiomatic and taken-for-granted views people have about the activity we colloquially refer to as "leadership." Some of these beliefs about leadership are so common and accepted as true that challenging them is counterintuitive, yet they can limit organizational effectiveness. In this article, we discuss four common leadership misunderstandings that contribute to the fabric of our self-evident, unexamined common sense view of leadership. Challenging these misconceptions provides the opportunity to create a new paradigm of leadership, one that could enhance organizational performance.
\end{abstract}

\section{Introduction}

Each of us, whether we know it or not, has an implicit leadership theory (ILT), a mental model we are largely unaware of, that represents what "good" leadership looks like and what it means to be an effective leader. First coined by Eden and Leviatan (1975), the theory posits that we each have a set of ideas and beliefs that delineate the kinds of "traits" - attributes, skills, and behaviors - that define effective leaders. These beliefs, variously referred to as "prototypes" or "schemas," affect the extent to which an individual accepts and responds to others as leaders.

ILTs are assimilated and learned from our social interactions, interpersonal encounters, and prior experiences with leaders. We categorize others as effective or ineffective leaders based on the perceived fit between their observed behaviors and the prototypical attributes of our existing ILT. Within this leadership context, being labeled a "good" or "bad" leader does not reflect an objective reality but rather mirrors the perceptual constructs that followers use to determine for themselves whether individuals in leadership positions are effective or not (Epitropaki \& Martin, 2004).

ILTs tend to operate outside of our conscious awareness but we would be ineffective without them. There would be no criteria for the type of faculty we recruit and no prototype for the kinds of leadership behaviors we emphasize. In Thomas Kuhn's words, "Something like a paradigm is prerequisite to perception itself. What a man sees depends both upon what he looks at and also upon what his previous visual-conceptual experience has taught him to see" (Kuhn, 1970). Not surprisingly, ILTs vary from person to person but they overlap in terms of the skills 
that leaders should possess in order to be effective (Forsyth, 2006). For example, in a study of medical school deans, integrity, trust, and vision were ranked as the most important leadership attributes, while authority and business acumen were rated as least essential (Souba, Mauger \& Day, 2007).

Curiously, the ILT literature has focused almost exclusively on the prototypical and ideal leadership attributes of individuals, overlooking the hidden and unchallenged beliefs and misconceptions people have about the activity called leadership. Some of these beliefs about leadership are so common and accepted as true that challenging them is counterintuitive, yet they can limit organizational effectiveness. Therefore, it is important to examine them and question them. Jim Kouzes and Barry Posner (2015) remind us that "our images of who's a leader and who's not are all mixed up in our preconceived notions about what leadership is and isn't." Thus, challenging these misconceptions should create new opportunities for exercising more effective leadership.

\section{Four Leadership Misconceptions}

In this article, we explore four common misconceptions about the phenomenon we colloquially refer to as "leadership." These misconceptions are so much a part of the fabric of our taken-for-granted common sense worldview of leadership (the prevailing paradigm) that it makes it difficult for many people to consider anything to the contrary (Table). Unveiling them and challenging them provides the opportunity to create a new paradigm of leadership, one that could enhance the performance of our universities and other organizations.

Table. Rethinking Leadership

Current Misconceptions Emerging Realities

Positional power is the leader's most important Language is the leader's most important lever resource

Leadership works by cause and effect, thereby providing an explanation for "good" or "bad" leadership outcomes

Leadership works as an entanglement phenomenon that provides $1^{\text {st }}$-person access to the source of leadership

Leadership decisions and actions are based on the objective facts

Our actions and interactions are consistent with the way in which we interpret (narrate) the facts

Knowledge is the foundational pillar of effective leadership

The leader's way of being is the foundation of his or her leadership effectiveness

\section{Misconception 1: Positional power (authority) is the leader's most powerful}

resource. At the heart of conventional leadership thinking is the notion that leadership is about a person in charge who stands apart, wields clout, allocates resources, and positions the organization so it can compete successfully and win. The cradle of the leader's performance in 
this model derives from his or her power, which is usually conferred by some title, rank, or achievement. The word "leader" often brings to mind vivid images: the visionary architect; the gifted teacher; the brilliant scientist; the savvy department chair. By and large, our view of leadership tends to center around visible individuals and their stature, contributions, and accomplishments. This view of leadership is not wrong per se, but it can be limiting. There are times when the "command and control" approach is an appropriate way of leading, but they are increasingly rare in flatter organizations that rely on shared leadership.

The emerging view of leadership contends that language, as opposed to power, is the leader's most valuable resource (Souba, 2010). According to this nascent model, title and clout are not essential prerequisites for exercising effective leadership. Said bluntly, the only requirement is the ability to communicate effectively. What leaders say and how they say it can make all the difference in the world. Imagine the diminished impact of Martin Luther King's words if he had said, "I have a business strategy" instead of "I have a dream."

Language serves two broad functions. In its descriptive (representational) role, it is used to represent or refer to things as they are now or have been in the past. The nature of this kind of communication is informational, descriptive, and comparative. Leaders use conversations in this sense to explain the organization's strategy or describe its core values. Language also has a generative, future-oriented (constitutive) purpose. Creating a new future is anchored in speech acts, utterances defined in terms of a speaker's intention and the effect it has on a listener (Austin, 1962; Searle, 1969). "We are attuned in everyday conversation," writes Mitch Green (2015), "not primarily to the sentences we utter to one another, but to the speech acts that those utterances are used to perform: requests, warnings, invitations, promises, apologies, predictions, and the like." Speech acts invariably use language that has the power to create new futures and initiate action. For example, a more concerted use of promises can improve organizational performance and morale in a short period of time. Don Sull (2007) points out that execution hinges on the quality of promises made and on the consistency with which those commitments are honored.

A vital part of a leader's responsibility is to motivate people. A view of language as constitutive recognizes that selves and communities are created through conversations. Many leaders, however, do not appreciate the generative power of language and resort to conventional oratory in an attempt to motivate people. This usually consists of a presentation in which they say, "Here's our company's biggest challenge, and here's our plan to deal with it." This approach is insufficient because people are not moved to act by reason alone - the more compelling way to enroll people is by telling an inspiring story about an alluring future (Brownyn, 2003). A good story expands our perspectives, allowing us to see options that heretofore were unavailable. Captivating stories can prompt cognitive shifts and jar people loose from their entrenched worldviews. "The story itself shapes our attitudes, actions, and reactions," notes Noel Tichy (2009). "Stories create real, human connections by allowing others to get inside our minds and our lives.... They engage listeners on an emotional and intuitive level that is rarely touched by the purely rational argument."

Because organizations are fundamentally networks and subnetworks of thousands of conversations, the nature of these storied interactions shapes the future. Creating a new future 
begins with helping people let go of their counterproductive conversations so there is room for new empowering stories to be woven into the cultural fabric (Souba \& Souba, 2018). Since a major cause of organizational inertia lives in the background stories and conversations that reinforce obsolete worldviews, creating organizational change involves shifting the network of conversations by intentionally bringing into existence and sustaining "new" conversations while completing the prevailing limiting conversations (Ford, 1999).

The implications of this shifting paradigm are profound. In the prevailing model, only those individuals with authority or clout can lead. In the emerging model, where language is the leader's most important resource, anyone can lead and, indeed, many more people must exercise leadership in today's complex world. Leaders who invite employees to offer advice, identify risks, and make recommendations, rather than simply issuing orders, generally elicit high levels of employee engagement (Groysberg \& Slind, 2012).

Many leaders overlook the importance of what they say and how they say it. But the quality of their leadership and their ability to get things done is largely a function of the words, sentences, and tone that comes out of their mouths. In the words of Kegan and Lahey (2001), "All leaders are leading language communities. Though every person, in any setting, has some opportunity to influence the nature of language, leaders have exponentially greater access and opportunity to shape, alter or ratify existing language rules.... The only question is what kind of language leaders we will be."

Misconception 2: Leadership works by the principle of causality. As human beings, we naturally assume that everything that happens in life is caused by something, i.e., every outcome is an effect of some cause. That assumption is our ordinary everyday self-evident and taken-for-granted worldview. For most of us, leadership operates under the same principles. Accordingly, the prevailing model says that a leader's performance is an effect (an outcome), where the cause of that effect is: a) the internal characteristics and attributes of the leader and/or b) the external circumstances with which that leader is confronted (Erhard, W, Jensen, M, \& Barbados Group, 2010). In other words, my effectiveness as a leader is caused by some combination of my abilities (skills) and/or some set of (favorable or unfavorable) external factors or conditions.

By way of illustration, suppose my boss asks me to help grow my sales revenue by establishing a stronger presence in the northwest part of town. We meet periodically to review my progress and at one point he asks me, "How have you managed to accomplish goal A but failed to accomplish goal B?" I almost automatically look for an answer from a cause/effect perspective. My performance, I assume unhesitatingly, has something to do with my knowledge, motivation, and genes and/or the external environment (e.g., the marketplace was kind or I got lucky or the marketplace shifted and I got caught in the crosswinds) in which I am leading. This taken-for-granted certainty that our actions are caused by our internal physiological and psychological state (our mental processes, feelings, thoughts, and attitudes) is so convincingly obvious that it makes it practically impossible for many people to take into consideration, much less critically examine, anything even slightly antithetical to that foregone conclusion. 
Not surprisingly, our efforts to enhance performance are largely based on improving the leader's skills (e.g., get a coach, take another course, get another degree) or doing something to alter the external dynamics in which the leader is leading (e.g., change strategies, invest more resources). This approach can be useful but it is often insufficient. Moreover, while the current cause-and-effect model of leadership performance provides reasons for the course of action the leader chooses, those reasons do not distinguish the source of one's actions, and as a consequence, currently provide no consistent access to producing real breakthroughs (Erhard, W, Jensen, M, \& Barbados Group, 2010).

The emerging model of leadership effectiveness approaches performance as an entanglement phenomenon (Souba, 2011). In this model, performance is a product of action (or inaction), where the leader's actions are entangled with (correlated with) the way in which whatever the leader is dealing with "occurs" for that leader and the way in which that leader occurs for himself or herself in dealing with that challenge (Erhard, W, Jensen, M, \& Barbados Group, 2010; Souba, 2011). [We borrow the term entanglement from quantum mechanics. Quantum entanglement is a phenomenon in which the quantum states of two objects can only be described with reference to each other, even though the individual objects may be separated by great distances.]

In other words, while factors such as experience certainly play a role in shaping the leader's actions, the emerging paradigm posits that the source of one's actions are first and foremost a function of the way in which the leader perceives and makes sense of the circumstances with which he or she is confronted. For example, if a leadership challenge shows up as unworkable, the leader's entangled actions will be very different than if the challenge shows up as one that is "hittable" (Souba, 2017).

Given this mutual relationship, reframing (recontextualizing, re-languaging) our leadership challenges such that they "occur" differently (i.e., we make sense of them through a different lens) is a critical, though often unrecognized, means by which we naturally "call forth" a different set of actions. Furthermore, given that reframing is always a linguistic process, language becomes the principle faculty leaders use to shift the way in which what they are dealing with occurs for them.

This is of critical importance because while we have little control of our thoughts and feelings, we do have complete say-so over what we say. Speaking differently alters the internal mental rehearsal such that the strengths of the connections of neurons that are wired together begin to change (Merzenich, 2013). With time, things occur differently. The idea that the way we perceive and understand our challenges in life is a function of what we have to say is nicely articulated by Lera Boroditsky (2008):

I used to think that languages and cultures shape the ways we think. I suspected they shaped the ways we reason and interpret information. But I didn't think languages could shape the nuts and bolts of perception, the way we actually see the world.... It turns out that languages meddle in very low-level aspects of perception, and without our knowledge or consent shape the very nuts and bolts of how we see the world. 
Thus, by way of language, we can alter (reframe) the way in which any leadership challenge shows up for us by altering what we say about it. For instance, consider this all too common view of the patient safety challenge that plagues all hospitals: "Breaches in patient safety are inevitable. Our surveillance and reporting systems take too much time. Patient safety is someone else's problem." Now consider this recontextualized view: "When we don't provide safe care, people suffer and people die." With "relanguaging", the patient safety challenge occurs in a very different light. Once the "occurring" shifts, our actions shift because the way in which our leadership challenge shows up (occurs) for us gives us our range of available actions for tackling it (Erhard, W, Jensen, M, \& Barbados Group, 2010). When patient safety breaches occur as someone else's problem, physicians' latitudes for action become quite limited and they often absolve themselves from taking full responsibility. Language matters - the way in which we say something has a profound effect on the brain's neural networks, which allows language to shape our actions (Wexler, 2006).

Check this phenomenon out for yourself. Let's say that your department chair does something to you that really frosts you - he reneges on his promise to put you up for promotion and tenure in July. All you hear from a senior colleague is that the chair decided now wasn't the time. You are furious because you've met all the criteria for promotion and someone you trusted has welshed on his word. You are boiling inside and your amygdala has gone haywire. You slam the door to your office behind you, storm up to the chair's office, rehearsing almost irrationally to yourself, "I'll show him!" Your outrage had to be caused by his duplicity, right? How could there be any other explanation? The fact of the matter is that the chair decided to not promote you; your interpretation (which you take to be a fact) is that his decision is wrong and should be reversed.

Half way up the stairwell, with your hand in a tight, white-knuckled fist, you pause. Your rational thinking, which was trumped initially by your emotions, starts to kicks in. "If I get in my boss' face," you tell yourself, "he could derail my future. I'd better back off." A few minutes ago you were on rails. But now, your rational brain has superseded and your interpretation of the facts changes. It occurs for you that the better part of valor is to retreat.

As preposterous as it seems, our actions are not compatible with the objective (actual) world "out there." Rather, our actions are always consistent (entangled) with the world as we perceive it, that is, the way in which the situation we are dealing with occurs (shows up) for us (Erhard, 2009; Souba, 2011). As soon as the occurring shifts, our actions shift. In the words of Karen Barad (2007), "To be entangled is ... to lack an independent, self-contained existence. Existence is not an individual affair. Individuals do not preexist their interactions; rather, individuals emerge through and as part of their entangled intra-relating."

The implications of this entanglement model of leadership are enormous. Good leaders recognize that our actions are not caused by our skills, our motivation, or our genes. Rather our actions, which determine our performance, are inextricably entangled with the way in which our leadership challenge occurs for us. And, the way in which the situation shows up for us is a function of our contextual frame, which is always linguistically constructed. Herein lies the power of this emerging model: it grants the leader direct access to the source of his or her performance because it is always accessible through language. Look again: If the leadership 
challenge you're dealing with occurs for you as hopeless or impossible, your way of being and acting will be consistent with that occurring. If the situation shows up for you as hopeful, your ways of being and acting will match it.

Misconception 3: Leaders make decisions and take actions based on facts. The taken-for-granted assumption that leaders make objective, rational decisions stems from the stature of scientific method, which is based on empirical evidence. Data-driven decision making is a hallmark of every good organization.

In The Structure of Scientific Revolutions, Kuhn (1970) challenged the deeply held belief that "different [leaders] confronting the same range of phenomena," would describe and interpret them in the same way and come up with the same "facts." He argued that the "facts" also depend on the person's social, cultural, historical, and scientific orientation. In other words, the scientific paradigm we live in involves more than empiricism; it depends on the community of peers to which the professional belongs. Observation and experience, notes Kuhn (1970), "cannot alone determine a particular body of such belief. An apparently arbitrary element, compounded of personal and historical accident, is always a formative ingredient of the beliefs espoused by a given scientific community at a given time." Virtually all research disciplines are "scientific" but they have "incommensurable ways of seeing the world and of practicing science in it."

When it comes to exercising leadership, ambiguity is the rule and, as all good leaders know, leadership is more of an art than a science. Efforts to change behavior - be they with memos, incentives, or inspirational speeches - only work some of the time with some organizational members in certain circumstances under certain conditions (for example, some department chairs complete their annual faculty performance evaluations on time, others require a terse reminder, still others never get them done). While strategic planning and budgeting are key activities that require data and facts, much of what leaders deal with on a day-to-day basis are competing conversations, big personalities, and a wide range of unpredictable behaviors. Our day-to-day construction of truth is far from objective. The way in which human beings construct the truth, especially inside the messy, subjective dynamics of our human interactions, is by way of narrative (McAdams \& McLean, 2013). According to Marshall Ganz (2007), "we make sense of the world in two ways - as narrative and as analysis. We develop our understanding of who we are, where we are going, and why as narrative. Narrative articulates how we feel about things (affect) better than what we think about them (cognition). The 'truth' of a story is in how it moves us." Said somewhat differently, we don't act in response to the facts; rather our actions and interactions reflect the way in which the facts occur for us.

The way in which the facts of any leadership challenge occur for us is shaped and swayed by our framing lenses, which are made up of our mental maps, beliefs, assumptions, and values that are, for the most part, hidden, biased, and unchallenged. We always "see" through our framing lenses, which explains why people act differently when confronted with the same set of circumstances. When we unveil these beliefs, values, assumptions, and attitudes, we discover that they reside in our narratives. Thus, framing lenses are also called narrative lenses. We are always looking at our leadership challenges through our accumulated, veiled framing lenses, which arise in, reside in, are accessible in, and are continuously molded by language. 
Narrative is the fundamental means through which people experience and live their lives but it is not an accurate record of what exactly happened; rather, it is a story we create to represent the way in which what happened was (is) experienced (Fisher, 1984). Knowledge is much broader than matters of fact. Human experience is always narrated, and human knowledge and personal identities are constantly being constructed in the process of social interaction. Barbara Hardy (1968) reminds us that "we dream in narrative, daydream in narrative, remember, anticipate, hope, despair, believe, doubt, plan, revise, criticize, construct, gossip, learn, hate, and love by narrative." In the domain of human relationships, perceptions trump actualities almost every time.

Narrative does not derive from an empirical model and the concept of truth is interpreted in a different way than in the empirical-analytical research tradition. For all practical purposes, effective leaders do not lead "theoretically." Rather, they lead "as-lived." Their self-narratives and their actions, as noted above, are entangled with the way in which the particular circumstances they are dealing with occur for them. Our narratives help us make sense of our experiences and provide continuity between the past and present. While we all have different life narratives, "truth" is a socially constructed understanding of the world that lives in language and forms the basis for shared assumptions about reality. In this light, Richard Rorty's (1986) words are spot on:

We need to make a distinction between the claim that the world is out there and the claim that the truth is out there. To say that the world is out there, that it is not our creation, is to say, with common sense, that most things in space and time are the effects of causes which do not include human mental states. To say that truth is not out there is simply to say that where there are no sentences there is no truth, that sentences are elements of human languages, and that human languages are human creations."

The three core components of scientific thinking - empiricism, rationalism, and skepticism (Hossain, 2014) - usually do not apply to our narrative truths. Our narrative truths are often unfounded (e.g., I could never get that job because I don't have an impressive résumé) and our beliefs are often illogical (I have to work very long hours to be successful). Moreover, once we are locked into a narrative, it can be quite difficult to challenge it much less change it. Nonetheless, our narratives are powerful because they reflect the way in which the world occurs for us.

The implications of leading with an awareness that we construct truth and take action not based on the facts but rather based on the way in which the facts occur for us are vast. To get to know people - what they care about and what is important to them - leaders must listen to their stories. Good leaders recognize that there is no truth per se, there are only different interpretations of reality. Meaning, therefore, becomes what is socially constructed by way of shared narratives.

Misconception 4: Knowledge is the ultimate foundation of effective leadership. In the prevailing leadership paradigm, knowledge is presumed to be the foundation of effective leadership (Souba, 2017). This approach to exercising leadership - using knowledge to unravel problems - is crucial for solving technical problems (e.g., your laptop crashes). However, this 
"third-person" approach, where learning to lead is based on using or acquiring someone else's knowledge about leadership, does not provide consistent "first-person" access to being a leader (Erhard, W, Jensen, M, \& Barbados Group, 2010).

In contrast to technical problems, adaptive (leadership) challenges are dilemmas for which the organization has no preexisting resources, tools, solutions, or even sensemaking strategies for accurately naming and describing the challenge (Heifetz, 1999; Day \& Halpin, 2014). Thus, they cannot be tackled adequately using knowledge because the know-how does not yet exist. Moreover, because adaptive challenges require solutions that lie outside the current inventory of organizational expertise, they require that we free ourselves from our hidden, longstanding beliefs and assumptions about leadership in order to find solutions. Access to these entrenched, hidden contexts begins with examining one's way of being, which always entails a first-person "as-lived/lived-through" learning approach. When these hidden framing lenses are unveiled, one can create new frames that offer more degrees of freedom to lead effectively. One unique advantage of this first-person approach is its power and utility, whether one already holds a major leadership position or has very little leadership experience. Consequently, "all organizational members need [to learn] to be leaders and all leaders need to be better prepared to participate in leadership (Day \& Halpin, 2014).

The emerging leadership paradigm distinguishes our way of being a leader as the basis for what leaders know and do. This model of leadership maintains that our framing lenses shape and constrain the way we lead and that these contexts are accessible through language. Michael Hyde (1983) explains:

How is [b]eing [a leader] revealed to man in and through the lived experience of his [leadership]?... The revelation of [b]eing is itself a linguistic experience; it occurs as objects of consciousness are interpreted such that they can be understood in a meaningful way.... Discourse brings the word to mind such that [what is being interpreted by the leader] can be thought and eventually made-known to others through communication practices.

Adaptive challenges can only be solved by people learning new ways of working them out, which begins by examining our ways of being. Four pillars of "being a leader" - awareness, commitment, integrity, and authenticity - have been proposed as foundational elements of an emerging leadership paradigm, which distinguishes being a leader as the basis for what leaders know and do (Souba, 2011). In taking a stand for our being, we can ask: From a position of awareness, commitment, integrity, and authenticity, how will I be in this particular situation right now? For example, when one is being a physician who takes a stand for the inviolability of the doctor-patient relationship, one naturally places service above reward.

For master leaders, the balance between knowing and being is always complementary. The being of leadership is primal and foundational but good leaders use their knowledge and expertise to illuminate, clarify, and inform the leadership challenges with which they are dealing. This partnership between being and knowing is also central to developing leaders. When one is a novice learning to lead, the purpose of training and education is to support the learner in becoming proficient in speaking the conventional language of leadership and learning to apply 
that language (Souba, 2010). However, while the road to leadership expertise always requires disciplinary literacy expertise, it also entails mastery of the language of leading oneself because organizational transformation must always be preceded by (or occur simultaneously with) personal transformation (Souba, 2015).

The implications of this paradigm swing are enormous. In the historical model, it was generally assumed that individuals who lacked the full scope of requisite knowledge could not lead effectively. But even more relevant to our challenges today, the shift in emphasis from knowing to being reflects the difference between organizational change and organizational transformation. Change is the result of using existing knowledge and expertise to alter (better, faster, and/or cheaper) what you are currently doing. Transformation, on the other hand, is about altering your way of being to create an outcome that until now has not been possible.

\section{The Work Ahead}

At a time when unpredictable, volatile change is the global norm, good leadership is arguably the most important organizational ingredient for ensuring long-term sustainable success. While it is virtually impossible to not have an implicit leadership theory, it is imperative that we continuously challenge our taken-for-granted leadership worldviews and mindsets. Without such cross-examination, improvements in the way in which we exercise leadership are unlikely to occur.

Challenging the long-standing taken-for-granted assumption that exercising leadership requires positional power is not about eliminating decision-making hierarchies. Rather, it is about recognizing that a title is not a prerequisite for leading. This distinction is critical at a time when more and better leadership from more people is essential. It is language, not power, that brings forth, out of the unspoken realm, innovative ideas and possibilities.

Most people are unaware that it is the way they perceive and make sense of their circumstances that is the actual source of their actions, masterful, inept, or otherwise. For example, Roger Federer does not play tennis masterfully simply by knowing how to serve and volley. Rather, he has come to inhabit the world of tennis. He has lived in that domain for decades such that the world of tennis uses him by granting him the being and actions of an expert tennis player. While Federer uses his athletic abilities to play tennis with great skill, the world of tennis also uses him to play the game. Similarly, master leaders do not lead effectively solely because they have a deep compendium of know-how and know-what about leadership. While such knowledge can be instructive and informative in specific situations, master leaders are used by the world of leadership, which grants them the being and actions of effective leadership.

Challenging these paradigms is counterintuitive because they make perfect sense to us and they worked in the past. Moreover, the process of confronting our taken-for-granted beliefs about leadership is often threatening. Nonetheless, questioning them is the first step in creating a better future. Donella Meadows' (1997) words are informative:

You could say paradigms are harder to change than anything else.... But there's nothing physical or expensive or even slow about paradigm change. In a single individual it can 
happen in a millisecond. All it takes is a click in the mind, a new way of seeing.... The highest leverage of all is to keep oneself unattached in the arena of paradigms, to realize that NO paradigm is "true," that even the one that sweetly shapes one's comfortable worldview is a tremendously limited understanding.

The willingness to challenge the four leadership misconceptions reviewed in this article is a characteristic of effective leaders. At the same time, good leaders are "sense givers"; they shape the way in which people understand themselves and others, and the way in which they work together. Because some understanding of the phenomenon we call leadership is both necessary and inevitable, we should strive to make that understanding as pragmatic as possible. Given the unprecedented leadership challenges we face as a planet, preparing leaders who exercise more and better leadership is, arguably, our most important responsibility going forward.

\section{References}

Austin, J. (1962). How to Do Things with Words. London: Oxford University Press.

Barad, K. (2007). Meeting the Universe Halfway: Quantum Physics and the Entanglement of Matter. Durham, NC: Duke University Press.

Boroditsky, L. (2008). Do our languages shape the nuts and bolts of perception, the very way we see the world? https://www.edge.org/response-detail/10138 Accessed 8/20/2017

Brownyn, F. (2003). Storytelling that move people. Harvard Business Review, 81(6): 51-55.

Day, D \& Halpin, S. (2014). Growing Leaders for Tomorrow: An Introduction. In: Leader Development for Transforming Organizations. Day, D, S Zaccaro, S Halpin (Eds.). Routledge: New York.

Eden, D \& Leviatan, U. (1975). Implicit leadership theory as a determinant of the factor structure underlying supervisory behavior scales. Journal of Applied Psychology, 60(6): 736-741.

Epitropaki, O \& Martin, R. (2004). Implicit leadership theories in applied settings: Factor structure, generalizability, and stability over time. Journal of Applied Psychology, 2004; 89(2): 293-310.

Erhard, W. (2009). How Language Shapes the World: A New Model Providing Actionable Access to the Source of Performance. 2009 NeuroLeadership Summit, Los Angeles. https://papers.ssrn.com/sol3/papers.cfm?abstract_id=1483082 Accessed 8/31/2017

Erhard, W, Jensen, M, \& Barbados Group. (2010). A New Paradigm of Individual, Group, and Organizational Performance. Harvard Business School NOM Unit Working Paper No. 11-006; Barbados Group Working Paper No. 09-02. https://ssrn.com/abstract=1437027 Accessed 7/13/2017. 
Fisher, W. (1984). Narration as human communication paradigm: The case of public moral argument. Communication Monographs, 51(1): 1-22.

Ford, J. (1999). Organizational change as shifting conversations. Journal of Organizational Change Management, 12(6): 480-500.

Forsyth, D. 2006. Group Dynamics. Wadsworth: Belmont, CA.

Ganz, M. (2007). What is public narrative? 2007. https://comm org.wisc.edu/syllabi/ganz/WhatisPublicNarrative5.19.08.htm Accessed 6/10/17

Green, M. Speech Acts. (2015). The Stanford Encyclopedia of Philosophy. Edward N. Zalta (ed.), URL = https://plato.stanford.edu/archives/sum2015/entries/speech-acts/ Accessed 8/10/2017.

Groysberg, B \& Slind, M. (2012). Leadership is a conversation. Harvard Business Review, 90(6): 76-84.

Hardy, B. (1968). Towards a poetics of fiction: An approach through narrative. NOVEL: A Forum on Fiction, 2(1):5-14.

Heifetz, R. (1999). Leadership without Easy Answers. Belknap Press. Cambridge, MA.

Hossain, F. (2014). A Critical Analysis of Empiricism. Open Journal of Philosophy, 4: 225-230. http://dx.doi.org/10.4236/ojpp.2014.43030 Accessed 8/14/2017.

Hyde, M. (1983). Rhetorically, man dwells: On the making-known function of discourse. Communication, 7: 201-220.

Kegan, R \& Lahey, L. (2001). How the Way We Talk Can Change the Way We Work. JosseyBass, San Francisco.

Kouzes, J \& Posner, B. (2015). Introduction. In: Edinger, S, Sain, L. The Hidden Leader. American Management Association: New York.

Kuhn, T. (1970). The Structure of Scientific Revolutions. University of Chicago Press: Chicago.

McAdams, D \& McLean, K. (2013). Narrative identity. Current Directions in Psychological Science, 22(3): 233-238.

Meadows, D. (1997). Places to Intervene in a System. http://www.wholeearth.com/issue/2091/article/27/places.to.intervene.in.a.system Accessed 8/8/2017.

Merzenich M. 2013. Soft-Wired: How the New Science of Brain Plasticity Can Change Your Life. $2^{\text {nd }}$ edition. Parnassus: San Francisco. 
Rorty, R. (1986). The Contingency of Language. London Review of Books, 8(7): 3-6.

Searle, J. (1969). Speech Acts: An Essay in the Philosophy of Language. Cambridge University Press: Cambridge, UK.

Souba, W. (2010). The language of leadership. Academic Medicine, 85(9): 1609-1618.

Souba, W. (2011). A new model of leadership performance in health care. Academic Medicine, 2011; 86(10): 1241-1252.

Souba, W. (2015). Health care transformation begins with you. Academic Medicine, 90(2): 139142.

Souba W. (2017). Hittability: The leader's edge. Academic Medicine, 92(4): 444-447.

Souba, W, Mauger, D, \& Day, D. (2007). Does agreement on institutional values and leadership issues between deans and surgery chairs predict their institutions' performance? Academic Medicine, 82: 272-280.

Souba, W \& Souba, M. (2018) How effective leaders harness the future. Academic Medicine, 93(2): 166-171.

Sull, D. (2007). Closing the gap between strategy and execution. MIT Sloan Management Review, 48(4): 31-38.

Tichy, N. (2009). The Leadership Engine: How Winning Companies Build Leaders at Every Level. Harper Collins: New York.

Wexler, B. (2006). Brain and Culture. MIT Press: Cambridge, MA.

\section{Author Biographies}

Wiley “Chip" Souba (chip.souba@ dartmouth.edu) is Professor of Surgery at the Geisel School of Medicine at Dartmouth. He has served as Dean of Medicine at two universities, Dartmouth and Ohio State. He has also served as Chairman of the Department of Surgery at Penn State. Chip is recognized for his innovative approaches to teaching leadership.

Matthew Souba (souba.2@osu.edu) is a doctoral student in philosophy at the Ohio State University. He is a graduate of Franklin and Marshall College. He completed a Master of Science degree in philosophy from the London School of Economics and a Master of Letters degree in philosophy from the University of St. Andrews in Scotland. 